\title{
Fatigue Analysis on Wheel considering Contact Effect Using FEM Method
}

\author{
Q. Y. Xiong, S. T. Yu, and J. S. Ju \\ College of Water Resources and Civil Engineering, China Agricultural University, Beijing 100083, China \\ Correspondence should be addressed to J. S. Ju; jasonnuig@gmail.com
}

Received 19 September 2014; Revised 10 January 2015; Accepted 18 January 2015

Academic Editor: Chenfeng Li

Copyright ( 2015 Q. Y. Xiong et al. This is an open access article distributed under the Creative Commons Attribution License, which permits unrestricted use, distribution, and reproduction in any medium, provided the original work is properly cited.

\begin{abstract}
The FEM model of whole wheel system, including wheel, axle, and track, was created by using solid element in ABAQUS. Stress distribution characteristic under self-weight condition was achieved when contact effect is considered. Then, material failure criterion was introduced to analyze the fatigue life of wheel system, which is influenced by surface processing and thermolizing. Meanwhile, fatigue distribution characteristic of all parts in the wheel structure system was also analyzed. The results show that the track's destructiveness is the most serious and has the shortest life, followed by the axle and the wheel. When the safety factor is set to be 2 , the destructiveness of the three parts is all more serious and the fatigue life is all shorter. Hot rolling and shot blasting have an unfavorable influence on fatigue life of wheel system.
\end{abstract}

\section{Introduction}

Railway has been a mainstay in transportation system [1]. Wheel system is one of the most important parts of railway transportation. In recent years, railway transport has developed toward the direction of the overload and high-speed in China. And high-power locomotive has already become increasingly prominent in this area. Locomotive wheel, as a component, can be operated in a very bad environment. During the working life, different types of loads, including static load, shake, dynamic load, and lateral loads, can lead to fatigue destructiveness [2-4].

Fatigue destructiveness damage is becoming more and more prominent with the soaring of traffic volume and the railway speeding-up; meanwhile it also put forward higher requirements on reliability and working life of important component in wheel system. Safety and working life, its important embodiment, are the two main product's performances. The wheel system reliability is directly related to these two aspects. Therefore, fatigue properties of wheel system have already been paid great attention by the railway engineers.

Fatigue problem can be divided into two parts according to whether or not to consider the cracks. One is nondestructive fatigue and the other is destructive fatigue. Generally speaking, it is conservative to consider the cracks, and most studies have concentrated on nondestructive fatigue.

In accordance with the value of cyclic stress, nondestructive fatigue can be divided into stress fatigue and strain fatigue. If the maximum cyclic stress outstrips the yield stress exceedingly, then it is called stress fatigue. Because of its low level of cyclic stress and higher life span, it is also called high cycle fatigue.

As for those with high load level (close to or beyond the yield stress) and shorter life span, then it is strain fatigue or low cycle fatigue. Material can determine its separation of life span, which corresponds to high and low cycle fatigue. With regard to these two separations, proper methods needed to be determined by considering material properties and research needs. Whether high cycle fatigue or low cycle fatigue, loading spectrum and material fatigue characteristic curve needed to be used in the analysis of fatigue. For the wheel system, high cycle fatigue will be analyzed.

At present, most of the research on fatigue life of wheel system aims at automobile wheel. Wang et al. [5] examined the reliability of wheel dynamic fatigue under constant amplitude loads and random loading spectrum and achieved distance-related curves of reliability under different road conditions. Zhou et al. [6] and Zheng et al. [7] numerically simulated the stress variation under different operating conditions 

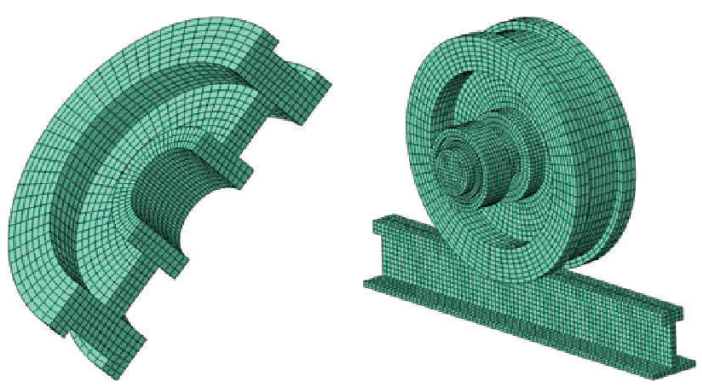

FIGURE 1: FEM model of the wheel system.

by using finite element method and analyzed spoke crack propagation characteristics under multiaxial loads. Firat et al. [8] proposed a computational methodology for fatigue damage assessment of metallic automotive components and its application is presented with numerical simulations of wheel radial fatigue tests. However, there are little reports on fatigue failure of locomotive wheel system. Vijayan et al. [9] developed finite element model of a three-piece mining wheel; the model predicted strains, for the majority of locations, within $15 \%$ error in comparison to experimental results.

In general, it can be seen that the research on fatigue properties of locomotive wheel system has not been fully carried out [10]. Moreover, there is still lack of research on locomotive wheel system fatigue caused by wheel-rail impact. In this paper, finite element model, including bearing, axle, wheel, and track, will be established to do static analysis. Stress distribution will be obtained for and used in building fatigue loading spectrum during the course of wheel impact. With the combination of material S-N curve and Miner linear damage cumulative standard [11], Fe-Fatigue module of the fatigue analysis software (nSoft) will be used to calculate the most dangerous unit and fatigue destructiveness within its working life. Fatigue properties studies are also included.

\section{Stress Calculation}

2.1. The FEM-Based Fatigue Analysis Process. Whether it is nondestructive fatigue or destructive fatigue, the basic fatigue analysis process by using finite element method is the same. First, fatigue experiment will be carried out to get the fatigue characteristic curve according to design requirements. Second, proper finite element model is being built to achieve stress and strain. Then fatigue loading spectrum can be established according to actual situation. Third, proper fatigue analysis type and method are selected. Forth, fatigue characteristic curve and fatigue loading spectrum should be combined together. Last, the calculation results are analyzed and evaluated with the comparison of experimental values.

2.2. Finite Element Model of Locomotive Wheel System. Due to the complex structure, only reasonable simplified model can make it possible to describe mechanical characteristics of the overall structure. In this paper, finite element model, including bearing, axle, wheel, and track, was established to do the strength calculation. In this way, stress distribution can also be obtained. In the process of modeling, element type of
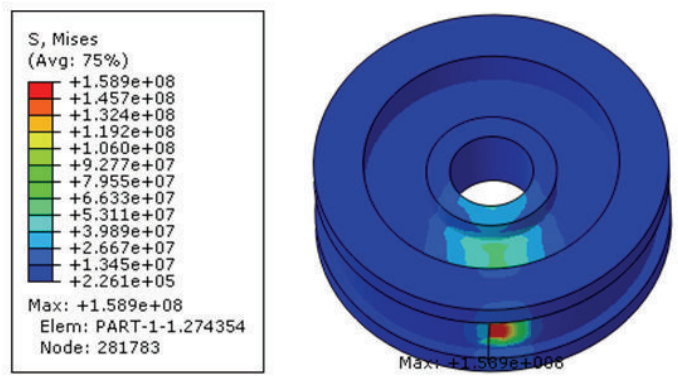

FIgURE 2: Mises stress of the wheel.

each part should be decided in the first place. Given computation time and cost, the selection of element with regular shape and fewer nodes should be based on the precision requirement. The reason for reducing the total number of nodes as many as possible is to effectively decrease the computational cost. 3D, 8 nodes linear brick, reduced-integration element (C3D8R) was adopted for the modeling. The meshed model shown in Figure 1 reveals that the total number of nodes is 14040 and total number of elements is 10944 .

Steel elastic modulus is $206 \mathrm{GPa}$, Poisson's ratio is 0.3 , and density is $7850 \mathrm{~kg} / \mathrm{m}^{3}$.

2.3. Boundary Conditions and Loads. In practical application, below the locomotive, track is fixed with $40 \mathrm{~mm}$ wide press plate at an interval of $600 \mathrm{~mm}$. Press plate is imposed with clamped supported constraints. In addition, via superstructure, self-weight can pass on to bearing. Then the load will be transferred from axle to the wheels. In this simulation, the vertical (negative $Y$ direction) load is applied in its bearing. The magnitude of load is determined according to the selfweight of the locomotive, and here the value is $50 \mathrm{t}$.

2.4. Calculation Results. The stress distribution of the locomotive wheel system is presented from Figure 2 to Figure 4.

As shown in Figure 2, the area, where the stress is more than $80 \mathrm{MPa}$, is located in the contact parts between wheel and track and the surface approaching wheel hub. The most dangerous element lies in the contact parts between wheels and tracks under self-weight. The magnitude of it is $158.9 \mathrm{MPa}$ and does not exceed yield stress. That is to say, the whole structure is in a certain condition of elastic range. Generally speaking, the bigger the fatigue damage, the shorter 


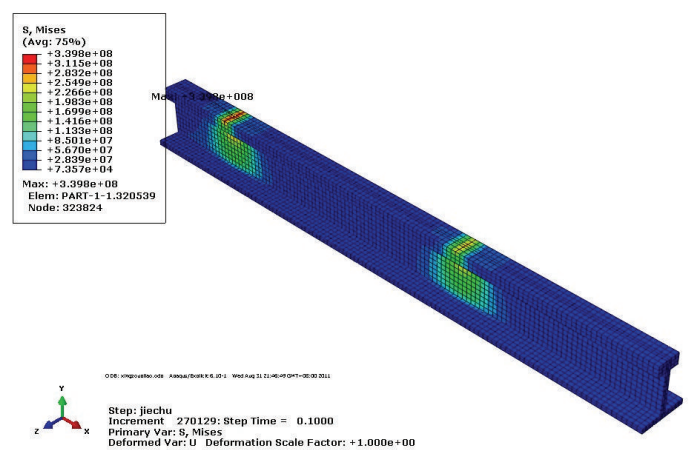

FIGURE 3: Mises stress of the track.

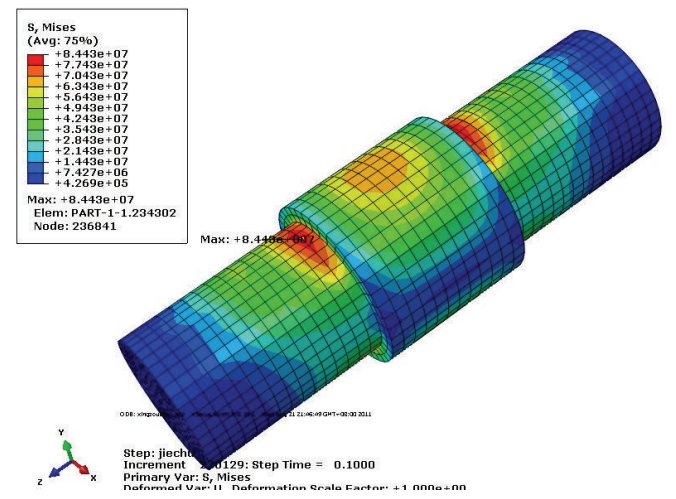

FIGURE 4: Mises stress of the axle.

the fatigue life. Therefore, in the process of fatigue analysis, stress concentration position is the emphasis.

As shown in Figures 3 and 4, the maximum stress of the track is $339 \mathrm{MPa}$ and happens on the contact surface between wheel and track. Stress concentration appears easily because of smaller contact area but larger load. For this reason, it is important to check track strength. The maximum stress of the axle is $84 \mathrm{MPa}$ and is much less than steel yield strength. It happens nearby variable cross section. The track is frequently in larger stress state. It is the emphasis for fatigue life problem of locomotive wheel system.

\section{Fatigue Life Calculation}

3.1. Loading Spectrum. When a crane or lifting trolley goes through the rough road or rail joints, operating impact load will be produced along the vertical direction and $\phi_{4}$ is the impact coefficient when considering this effect. Operating impact coefficient is related to the running speed, track, and road conditions of the crane or lifting trolley.

As for the track joint in good condition, like welded connection with polished joint of high-speed operation crane, the value of $\phi_{4}$ is 1 . As for the track joint in general condition, vertical impact effect will be generated and $\phi_{4}$ can be determined by the following formula [12]:

$$
\phi_{4}=1.1+0.058 v_{y} \sqrt{h}
$$

where $\phi_{4}=$ operating impact coefficient; $v_{y}=$ running speed of the crane, $\mathrm{m} / \mathrm{s} ; h=$ altitude difference between surface of the rail joints, $\mathrm{mm}$.

According to the relevant specification and formulas, vertical impact load produced in the operating process is determined and fatigue loading spectrum is built. From the above formula, operating impact coefficient is proportional to its running speed. In this paper, working condition of $72 \mathrm{~km} / \mathrm{h}$ in running speed will be selected to calculate fatigue life.

Thus, the loading spectrum is set up as shown in Figure 5 and it represents one stress circle in one fatigue period. The horizontal axis represents the time or impact time of the walking mechanisms, and it is decided by the length of joints at regular intervals. When the standard length of the track is $25 \mathrm{~m}$, the impact period is $1.25 \mathrm{~s}$. The maximum value is just set to 2.16 (corresponding to the juncture moment) in the method of FE-Fatigue-EN and the minimum is 1 (corresponding to the normal walking moment). During the calculating process of FE-Fatigue Analysis module, actual loading spectrum will be got by stress calculation results multiplying the loading spectrum in the file of ABAQUS.fil. The numerical value refers to stress coefficient in Figure 5.

3.2. Material Selection. As fatigue property experiment has not been carried out yet, there have not been standard S-N curve and E-N curve. In this paper, yield stress approaching those of the real wheel will be selected from nSoft material library to carry out the analysis of fatigue life. In the end, material type will be set to SAE1045_HV_HR. Due to the complete E-N curve data, the E-N method is chosen to analyze fatigue life of the locomotive wheel system.

E-N method mainly takes the strain as the input signal and also with stress data in finite element calculation. The fatigue analysis software nSoft can change stress-strain curve into strain signal. Meanwhile, it can correct the elastic stressstrain curve into cyclic stress-strain curve, and then elasticplastic stress-strain curve is formed. Uniaxial transforming method is Neuber method and biaxial method is HoffmannSeeger method. It is a must to consider plasticity, and cyclic stress-strain curve can tell if the material has gone into plasticity [13].

3.3. Strain Calculation of Fatigue Life. In this section, the finite element calculation results are imported into nSoft. Then, the maximum shearing strain is selected as stress-strain standard. SWT method is chosen to correct average strain and Hoffmann-Seeger method for elastic-plastic modification. Other parameters are set to be default. Material type is set to SAE1045_HV_HR with forged surface roughness and nitrided surface heat treatment. By using loading spectrum in Figure 5 to calculate fatigue life of locomotive wheel system, the results are obtained as shown from Figure 6 to Figure 11. Figures 6, 8, and 10 show destructive nephogram of the wheel, track, and axle, respectively; Figures 7, 9, and 11 show the corresponding life span nephogram.

If the life span exceeds $1 E 8$ in nSoft, it will be displayed in Beyond Cutoff. It means the calculation outstrip computer capacity and called infinite life span. From Figures 6 and 7 , it can be seen that the location of the wheel's maximum 


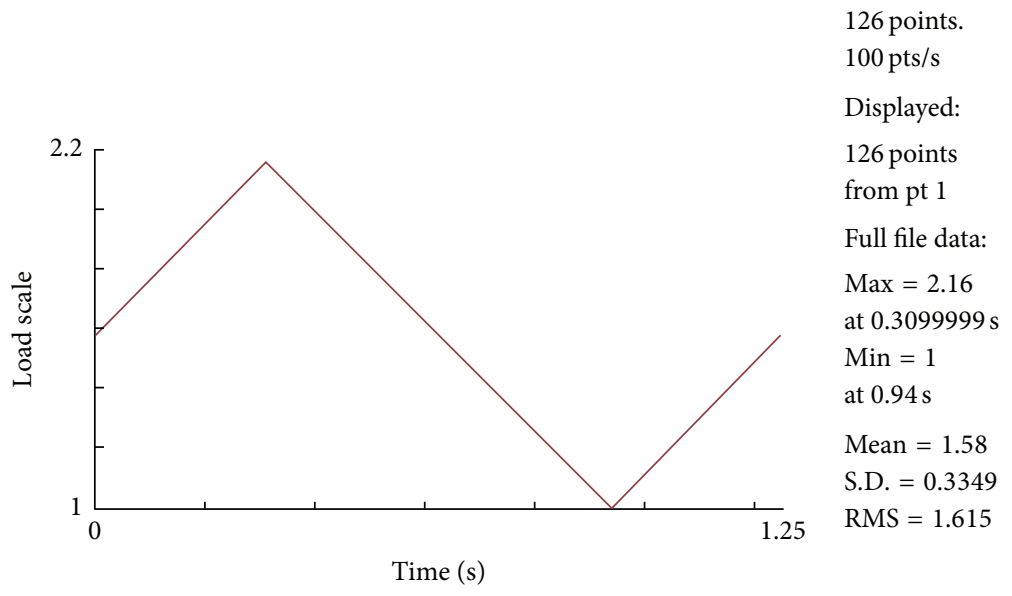

FIGURE 5: Loading spectrum of FE-Fatigue method.

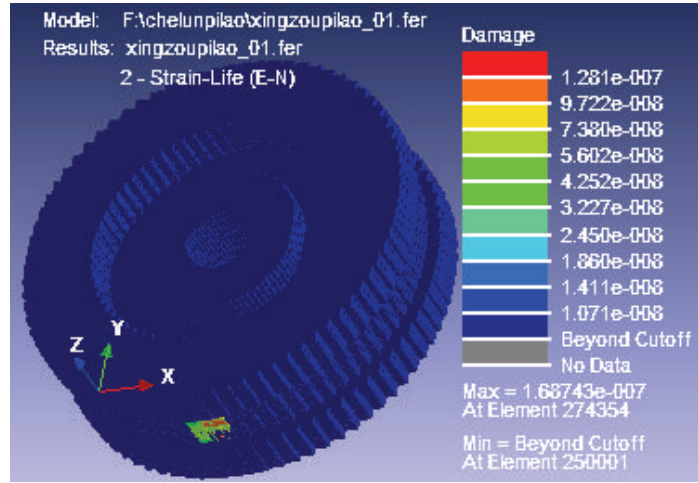

FIGURE 6: Destructive nephogram of the wheel.

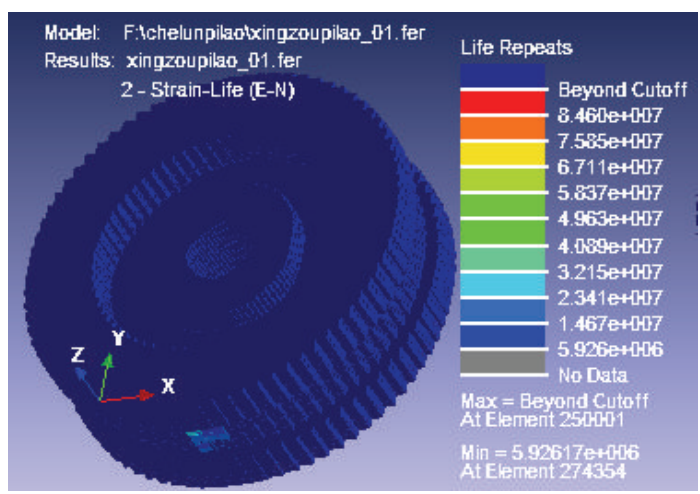

FIgURE 7: Life span nephogram of the wheel.

destructiveness is in the contact part between wheel and the track. The destructive value of the most dangerous point is $1.687 E-7$ and the shortest life span is 5.926E6. Most of the wheel region is in the infinite life area. After converting cyclic stress-strain curve into a new one, stress-strain is still in high cycles. When assessing fatigue life of the wheel, the shortest life span is the only concerning point in most cases. Choosing it as the whole value of life span, the locomotive wheel can

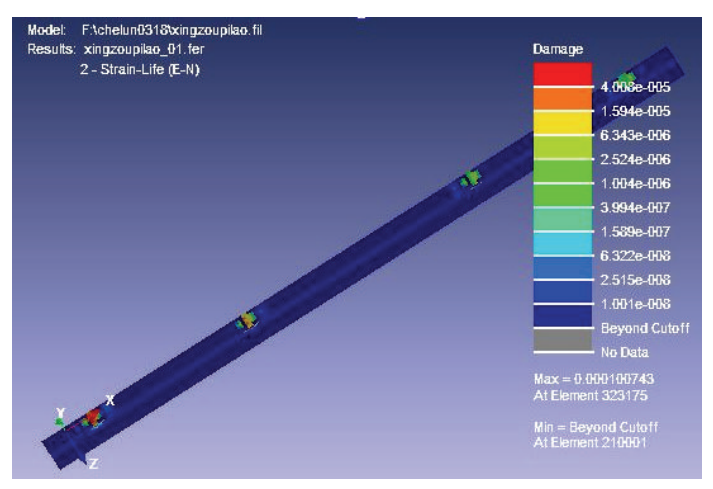

FIGURE 8: Destructive nephogram of the track.

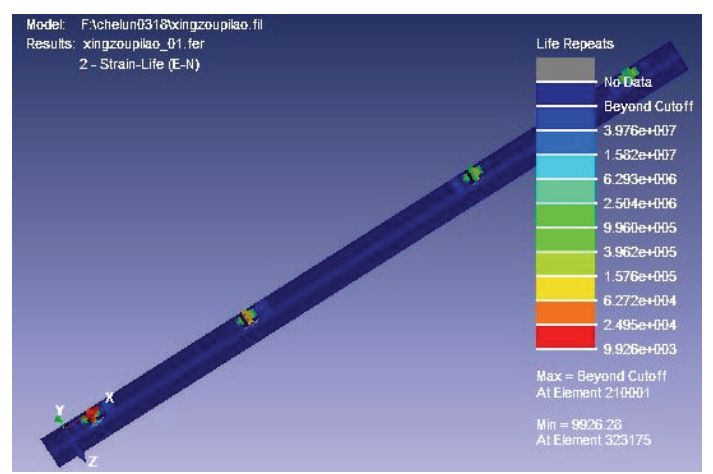

FIGURE 9: Life span nephogram of the track.

pass through the stimulating process of loading spectrum for 5.926E6 times.

From Figure 8 to Figure 11, it can be seen that the location of the track's maximum destructiveness is in the contact part between track and the wheel, and the value is $4.008 E-5$. The corresponding shortest life span is 9928 which is much less than that of the wheel. The maximum destructiveness value of the axle is $7.374 E-6$ and it happens in variable cross section. The corresponding shortest life span is 6.512E4. It is thus clear 


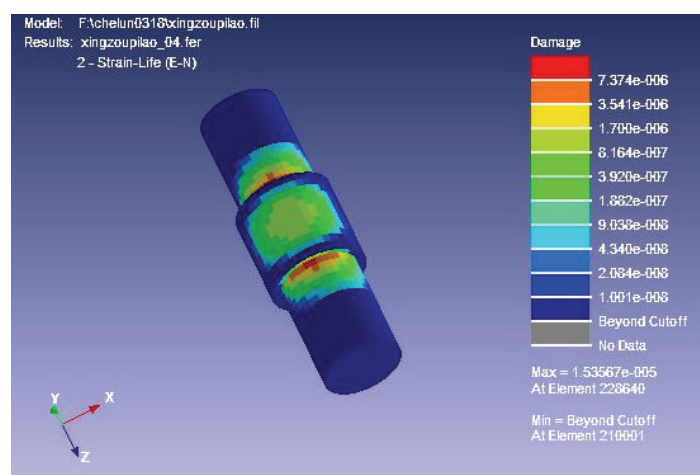

FIGURE 10: Destructive nephogram of the axle.

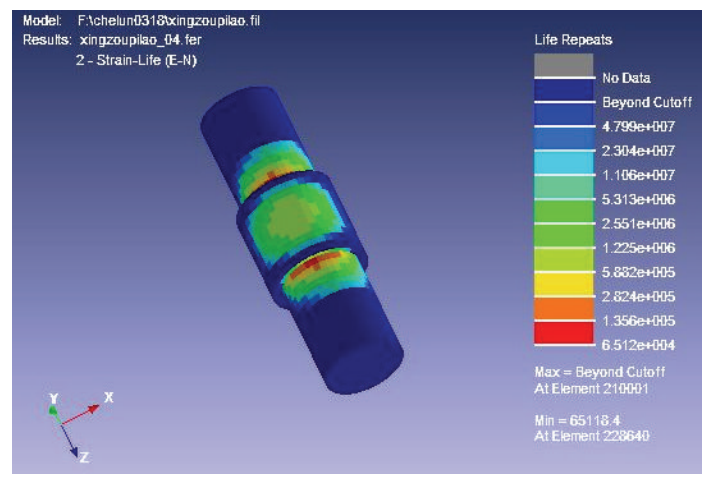

FIgURE 11: Life span nephogram of the axle.

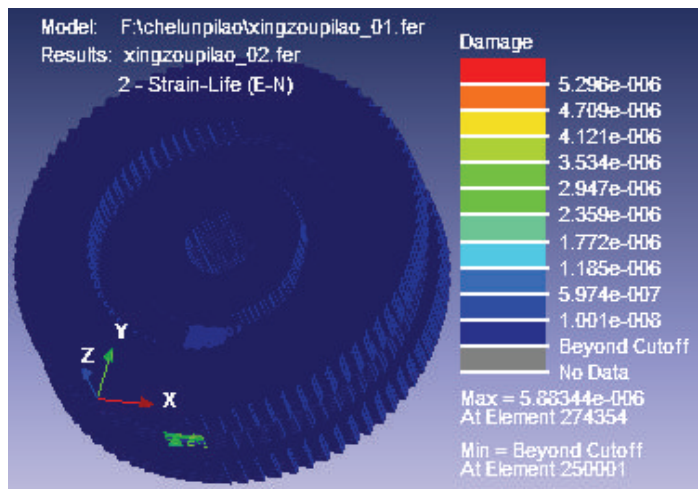

FIGURE 12: Destructive nephogram of the wheel (safety factor is set to be 2).

that the location with the maximum destructiveness value is often the same as that with the maximum stress, and the shortest life span also happens in those locations. That is to say that the structure service time depends on those locations.

In order to better research the fatigue property of locomotive wheel system and suggest properly for fatigue life design, safety factor is set to be 2 , that is to say, magnifying loading spectrum twice and calculating again. The results are shown from Figure 12 to Figure 17. Figures 12, 14, and 16 show destructive nephogram of the wheel, track, and axle, respectively; Figures 13, 15, and 17 show the corresponding life span nephogram.

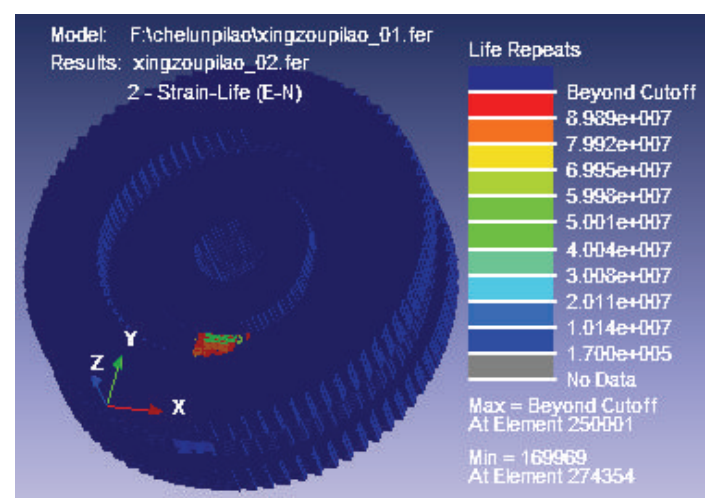

FIGURE 13: Life span nephogram of the wheel (safety factor is set to be 2).

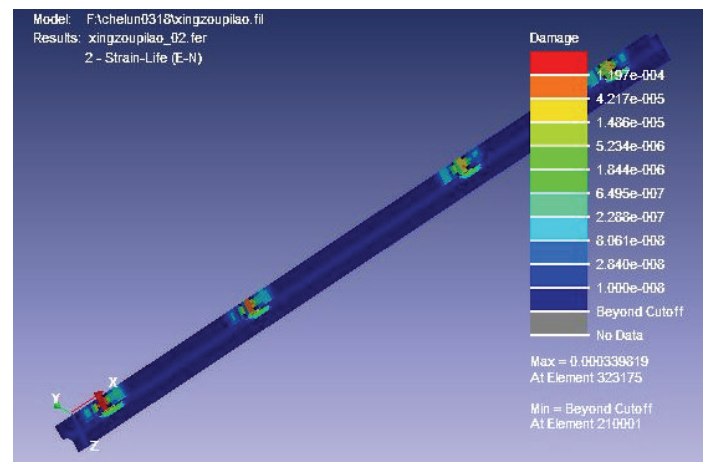

FIGURE 14: Destructive nephogram of the track (safety factor is set to be 2).

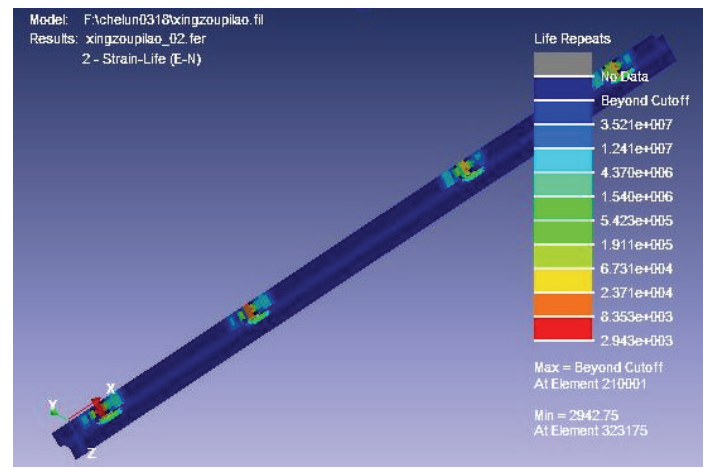

FIGURE 15: Life span nephogram of the track (safety factor is set to be 2).

From Figures 12 and 13, it can be seen that the location of the wheel's maximum destructiveness is still in the contact part between wheel and the track. The destructive value of the most dangerous point is $5.883 E-6$ and the shortest life span is $1.700 E 5$. Most of the wheel region is in the infinite life area. After converting cyclic stress-strain curve into a new one, stress-strain is still in high cycles. In addition, there is a higher destructive value and shorter life span in the surface approaching wheel hub. 


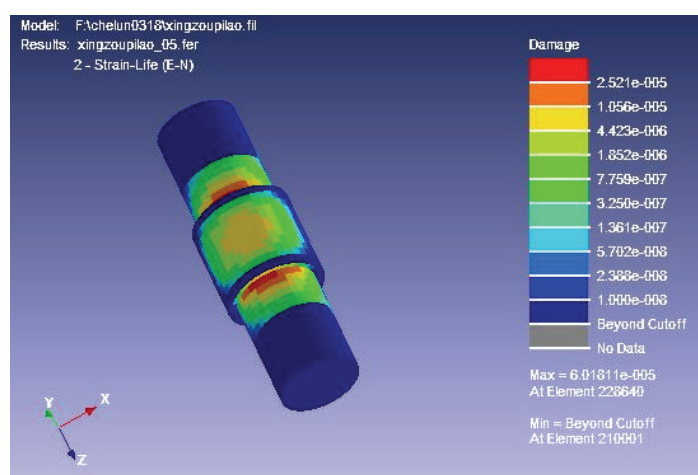

FIGURE 16: Destructive nephogram of the axle (safety factor is set to be 2).

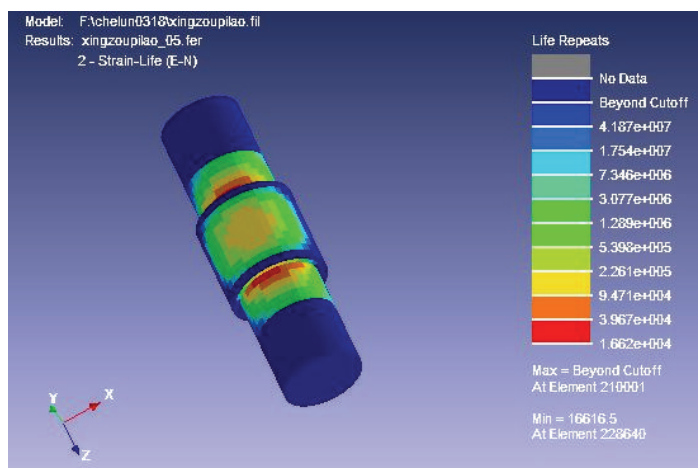

FIGURE 17: Life span nephogram of the axle (safety factor is set to be 2).

As shown from Figure 14 to Figure 17, it can be seen that the location of the track's maximum destructiveness is in the contact part between track and the wheel, and the value is $1.197 E-4$. The corresponding shortest life span is 2943 . The maximum destructiveness value of the axle is $2.521 E-5$ and it happens in variable cross section. The corresponding shortest life span is 1.662E4. It is thus clear that the maximum destructiveness value of both the track and the axle is larger than that in normal service state and the corresponding life span is much less when safety factor is set to be 2 .

In the actual project, the way to processing and thermolizing the surface of parts has a great influence on fatigue life. nSoft just provides various kinds of processing methods, such as polishing, hot rolling, forging, and seawater corrosion. The degree of influence largely depends on different surface processing methods. It corresponds to surface modifying factor, and if the modifying factor is less than 1, the life span would become shorter when considering the same loading spectrum. The more abominable the surface appearance is, such as casting and water erosion, the bigger the destructive value is and the shorter the life span is. Moreover, there are four surface processing methods about thermolizing, that is, nontreatment, nitriding, cold rolling, and shot blasting. Thermolizing is good to reduce the mean stress of the material surface, especially the average normal stress. According to fatigue theory, the lower the average stress, the higher the

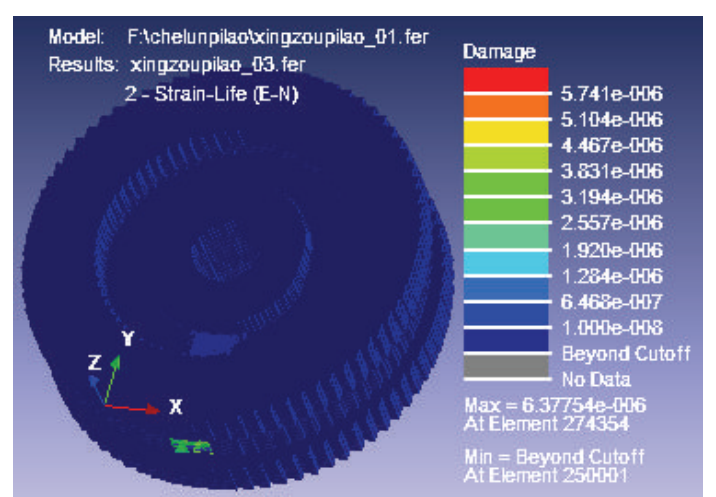

FIGURE 18: Destructive nephogram of the wheel (hot rolling and shot blasting).

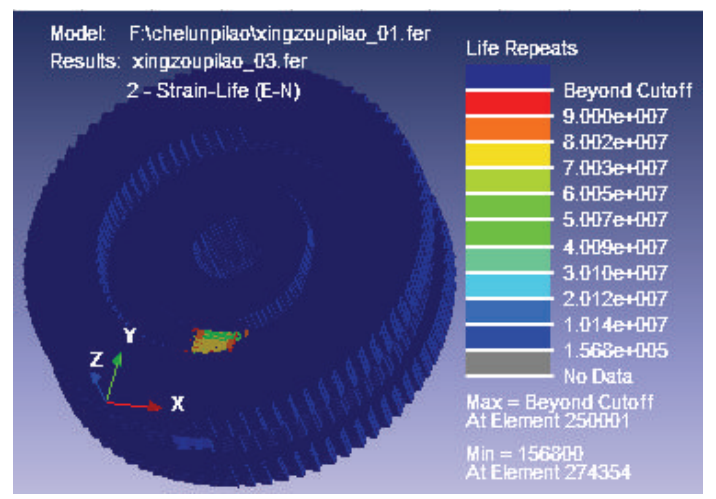

FIGURE 19: Life span nephogram of the wheel (hot rolling and shot blasting).

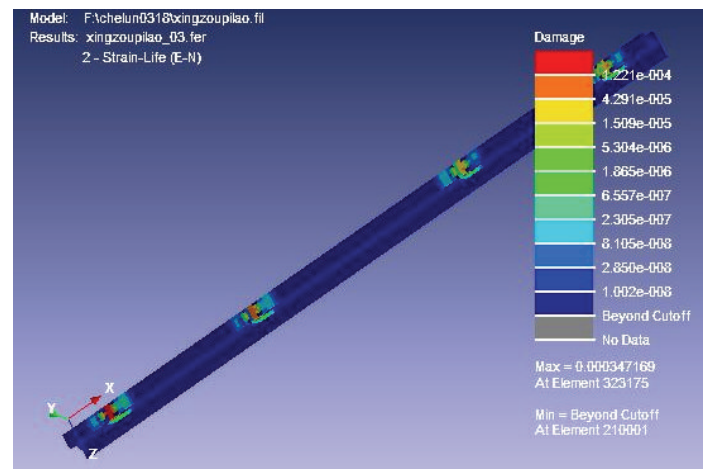

FIGURE 20: Destructive nephogram of the track (hot rolling and shot blasting).

life span will be in the same loading spectrum. Therefore, life span will be improved after thermolizing.

Now, the surface processing method is changed into hot rolling, and thermolizing is changed into shot blasting. The influence on fatigue life of locomotive wheel system caused by the two factors is analyzed. The results are shown from Figure 18 to Figure 23. Figures 18, 20, and 22 show destructive nephogram of the wheel, track, and axle, respectively; Figures 19,21 , and 23 show the corresponding life span nephogram. 


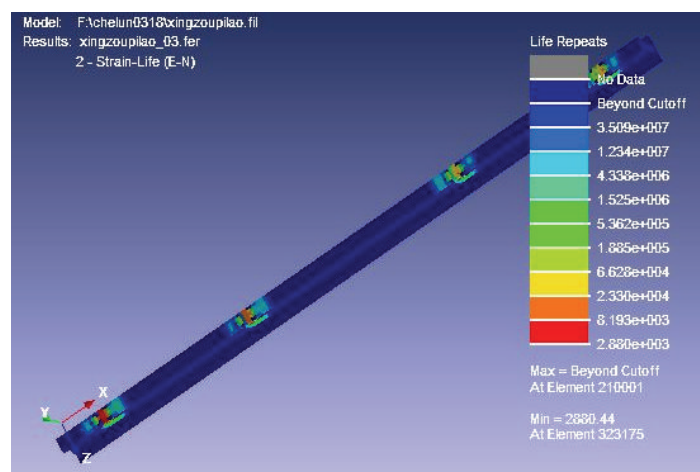

FIGURE 21: Life span nephogram of the track (hot rolling and shot blasting).

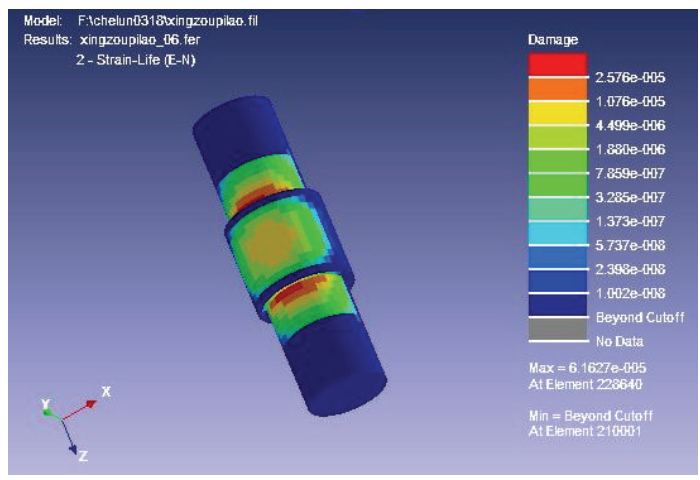

Figure 22: Destructive nephogram of the axle (hot rolling and shot blasting).

From Figures 18 and 19, it can be seen that the location of the wheel's maximum destructiveness is in the contact part between wheel and the track. The destructive value of the most dangerous part is $6.378 E-6$ and the shortest life span is $1.568 E 5$. Most of the wheel region is in the infinite life area. In addition, there is still a higher destructive value in the surface approaching wheel hub.

As shown from Figure 20 to Figure 23, it can be seen that the location of the track's maximum destructiveness is in the contact part between track and the wheel, and the value is $1.221 E-4$. The corresponding shortest life span is 2880 . The maximum destructiveness value of the axle is $2.576 E-5$ and it happens in variable cross section. The corresponding shortest life span is $1.623 E 4$. It is thus clear that the maximum destructiveness value of both the track and the axle is larger than that in normal service state and the corresponding life span is much less when the surface processing method is hot rolling and thermolizing is shot blasting.

\section{Conclusions}

Based on the results of this investigation, the following conclusions can be drawn.

(1) Most of the wheel region is in the infinite life area. The location of the wheel's maximum destructiveness is in the contact part between wheel and the track.

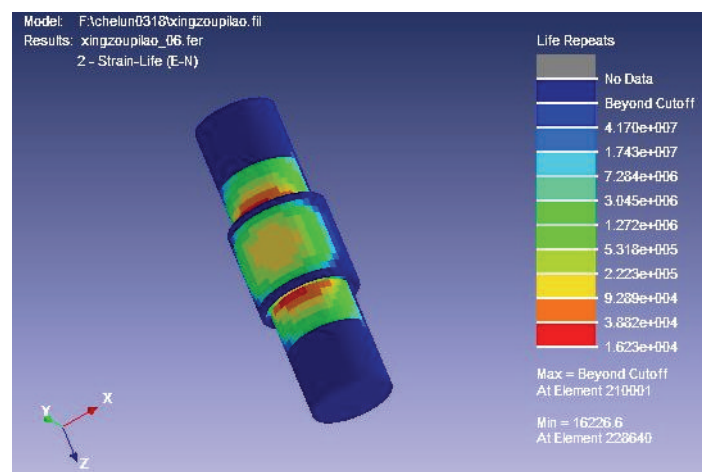

FIGURE 23: Life span nephogram of the axle (hot rolling and shot blasting).

The destructive value of the most dangerous part is $1.687 E-7$ and the shortest life span is 5.926E6. The location of the track's maximum destructiveness is in the contact part between track and the wheel, and the value is $4.008 E-5$, and the corresponding shortest life span is 9928 . The maximum destructiveness value of the axle is $7.374 E-6$ and it happens in variable cross section. The corresponding shortest life span is $6.512 E 4$. For the three parts, the track's destructiveness is the most serious and has the shortest life, followed by the axle and the wheel.

(2) When safety factor is set to be 2 , the destructive value of the wheel, track, and axle will all increase remarkably with life span decreasing sharply. The location of the wheel's maximum destructiveness is still in the contact part between wheel and the track. The destructive value of the most dangerous part is $5.883 E-6$ and the shortest life span is 1.700E5. The location of the track's maximum destructiveness is in the contact part between track and the wheel, and the value is $1.197 E-4$, and the corresponding shortest life span is 2943. The maximum destructiveness value of the axle is $2.521 E-5$ and it also happens in variable cross section. The corresponding shortest life span is 1.662E4. It is thus clear that the destructiveness of the three parts is all more serious and the fatigue life is all shorter.

(3) When the surface processing method is changed into hot rolling and thermolizing into shot blasting, the destructive value will experience a slight increase with shorter life span. Compared with forging and nitriding, hot rolling and shot blasting have an unfavorable influence on fatigue life of locomotive wheel system.

\section{Conflict of Interests}

The authors declare that there is no conflict of interests regarding the publication of this paper. 


\section{Acknowledgments}

This research was supported by National Science Foundation of China (51279206) and Beijing Natural Science Foundation (3144029).

\section{References}

[1] C. Xu, Research on Shape Optimization of Parameterization and Wheel Fatigue Strength, Southwest Jiaotong University, Chengdu, China, 2009.

[2] X. Dong, Reliability Engineering on Vehicle Application, China Railway Press, Beijing, China, 2002.

[3] H. Xia, Dynamic Interaction between Vehicle and Structure, Science Press, Beijing, China, 2002.

[4] M. Diener and K. Yao, "Research on breaking mechanism of the wagon wheel and the metal science," Journal of Locomotive Vehicle Technology, no. 2, pp. 18-24, 1993.

[5] X. Wang, Y. Zhang, and B. Wang, "Research on reliability-based dynamic fatigue of locomotive wheels," Journal of Engineering Design, vol. 16, no. 4, pp. 247-251, 2009.

[6] S.-X. Zhou, X. Nan, and X. Jilong, "Research on crack propagation characteristic of railway wheel with web plat under multiaxial loading," Journal of Engineering Mechanics, vol. 27, no. 1, pp. 41-46, 2010.

[7] H. Zheng, J. Xie, S. Zhou, and B. Feng, "Multi-axial fatigue strength analysis of wheel based on FEA," Journal of Beijing Jiaotong University, vol. 33, no. 4, pp. 54-59, 2009.

[8] M. Firat, R. Kozan, M. Ozsoy, and O. Hamdi Mete, "Numerical modeling and simulation of wheel radial fatigue tests," International Journal of Heavy Vehicle Systems, vol. 17, no. 2, pp. 159-178, 2010.

[9] V. Vijayan, W. Altenhof, and R. Banting, "A finite element approach for prediction of fatigue life for a three-piece mining vehicle wheel," Engineering Failure Analysis, vol. 16, no. 8, pp. 1533-1541, 2008.

[10] J. Hu, K. Chen, and X. You, "The research of long steam turbine blade on low cycle fatigue characteristic," in Proceedings of the Mechanics and Engineering Application, pp. 162-170, Shanghai Society of Mechanics, Shanghai, China, 2010.

[11] J. Hu, Research on Fatigue Characteristics of Large-Volume Half-Speed Long Nuclear Power Steam Turbine Blade, Tsinghua University, Beijing, China, 2011.

[12] G. Wang, R. Hu, and X. Chen, NSoft Fatigue Analysis Theory and the Application Examples, China Machine Press, 2007.

[13] "nSoft online documentation, V5.3," 2003, UK. nCode. 


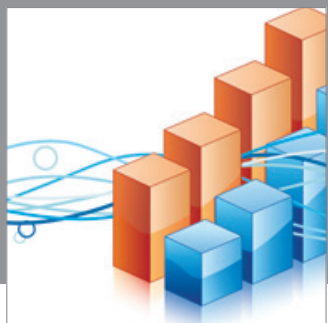

Advances in

Operations Research

mansans

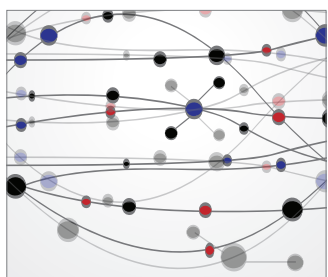

The Scientific World Journal
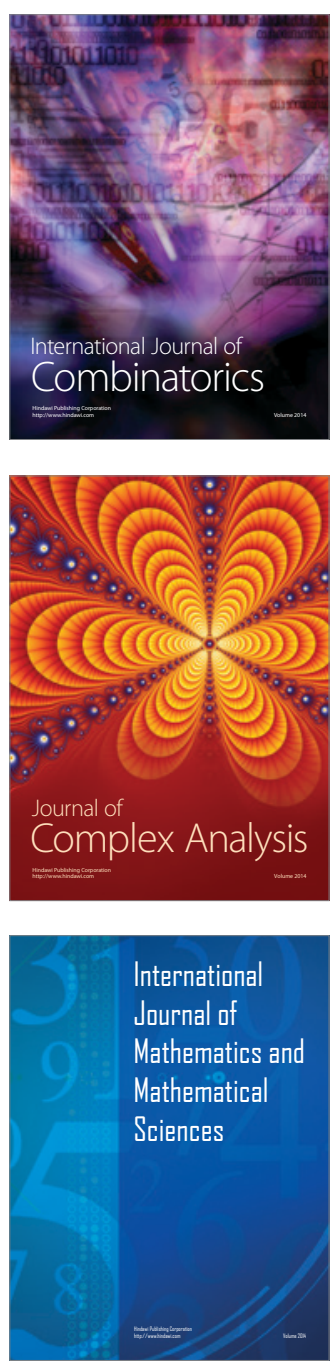
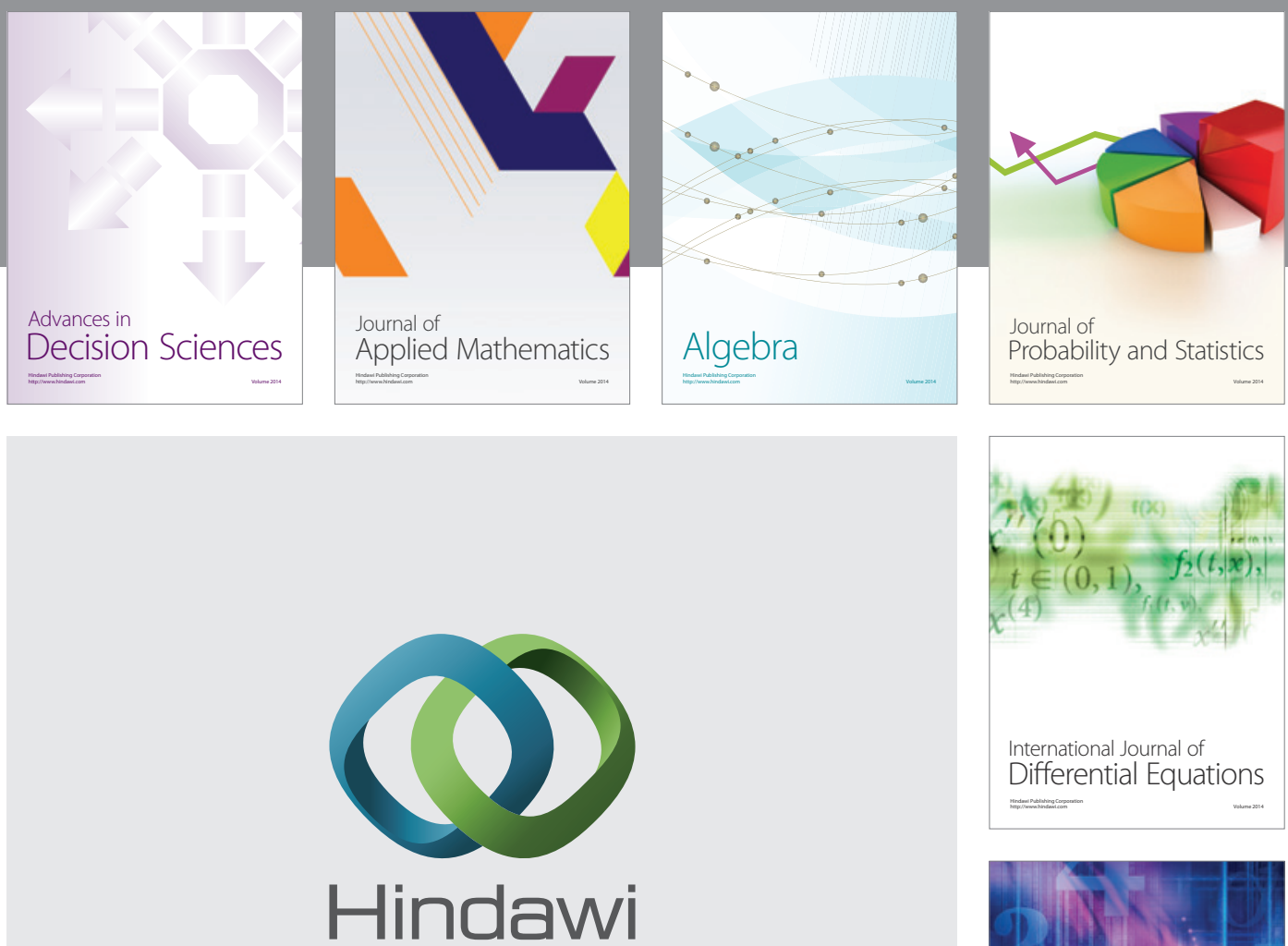

Submit your manuscripts at http://www.hindawi.com
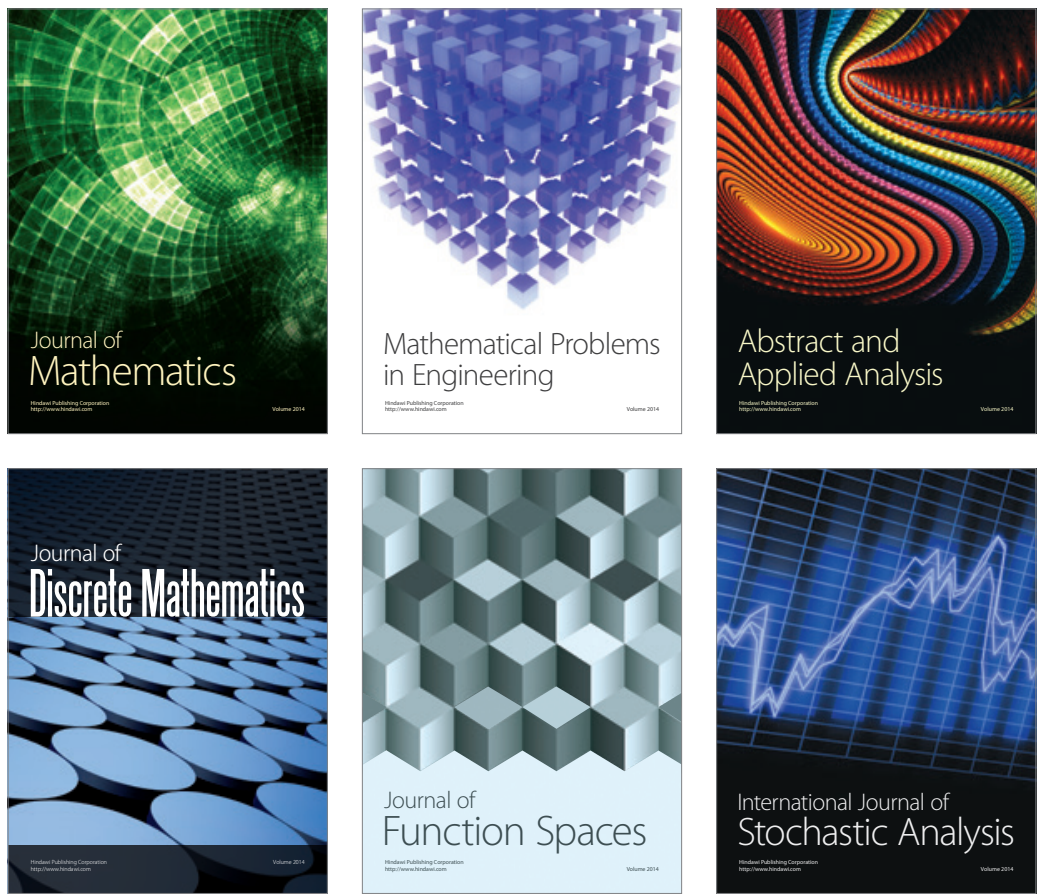

Journal of

Function Spaces

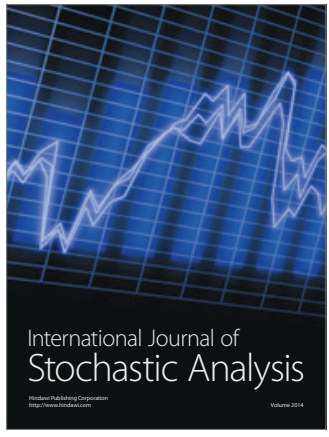

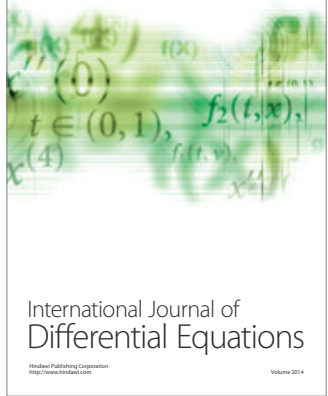
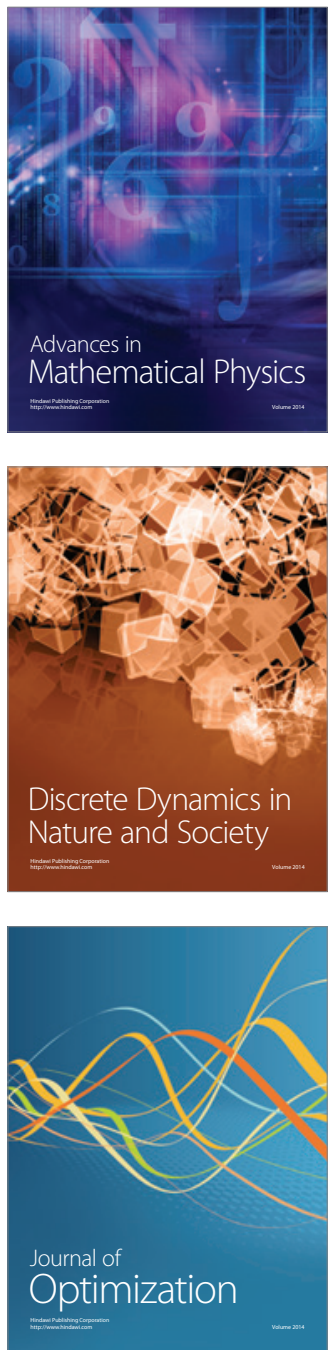